\title{
KEY FACTORS FOR SUSTAINABLE RATIONAL USE OF MEDICINE PROGRAM IN GUNUNGKIDUL AND SLEMAN DISTRICTS, INDONESIA
}

\author{
SUNARTONO $\mathrm{H}^{1 * \dagger}$, PRABANDARI YS ${ }^{2}$, KUSNANTO $\mathrm{H}^{2}$, SURYAWATI $\mathrm{S}^{3 \dagger}$ \\ ${ }^{1}$ Division of Clinical Pharmacology and Medicine Policy, Department of Pharmacology and Therapeutics, Faculty of Medicine, Universitas \\ Gadjah Mada, Yogyakarta, Indonesia. ${ }^{2}$ Department of Health Policy and Management, Faculty of Medicine, Universitas Gadjah Mada, \\ Yogyakarta, Indonesia. ${ }^{3}$ Division of Clinical Pharmacology and Medicine Policy, Department of Pharmacology and Therapeutics, Faculty of \\ Medicine, Universitas Gadjah Mada, Yogyakarta, Indonesia. Email: sunartonosekda@gmail.com \\ ${ }^{\dagger}$ Equal contribution \\ Received: 19 September 2017, Revised and Accepted: 31 October 2017
}

ABSTRACT

Objective: Many of the rational use of medicines (RUM) interventions have been proven effective in improving medicine use, but the impacts were usually not sustainable for longer period of time. Gunungkidul and Sleman Districts of Indonesia have succeeded in implementing RUM program for more than two decades. This is considered rare, and therefore, it is important to identify factors contributing to the success.

Methods: This is a single case study with non-experimental exploratory design. Quantitative and qualitative data were collected integratively to obtain information concerning the indicators and the process of RUM implementation. Quantitative data were collected in reference to the World Health Organization (WHO) 1993 RUM indicators, including average number of medicines per prescription (polypharmacy), percentage of patients receiving antibiotics, and percentage of patients receiving injections. Qualitative data were analyzed descriptively and were arranged chronologically in respective to each district.

Results: Implementation of RUM in the two districts has successfully lasted up to 20 years. The annual medicine use indicators from 1994 to 2014 in Gunungkidul District show that polypharmacy decreased from 4.2 to 2.89 , percentage patients receiving injections declined from $68.05 \%$ to $0 \%$, and percentage of patients receiving antibiotics improved from $52.1 \%$ to $24.1 \%$. The same indicators in Sleman District show that, between 1998 and 2014, polypharmacy remained stable at 3, percentage of patients receiving injections declined from $4.9 \%$ to $0.18 \%$, and percentage of patients receiving antibiotics improved from $44.31 \%$ to $20 \%$. Culturization of RUM program is the main key for sustainable impacts. Another important key is the high commitment of health policymakers to implement the principles of evidence-based treatment.

Conclusions: The culturization of RUM program followed by continuous monitoring and evaluation by district health managers were the key factors to maintain the impact of the intervention.

Keywords: Rational use of medicines, Culturization, Program implementation, Sustainability.

(c) 2018 The Authors. Published by Innovare Academic Sciences Pvt Ltd. This is an open access article under the CC BY license (http://creativecommons. org/licenses/by/4. 0/) DOI: http://dx.doi.org/10.22159/ajpcr.2018.v11i2.22653

\section{INTRODUCTION}

Discoveries of new medicines have given positive impacts in the medical world. However, for providing medicines in public services, government should select medicines based on the strongest scientific evidence despite the individual reactions to the same medicines. That is why treatment guides, and list of essential medicines continuous monitoring of rational use of medicine (RUM) are necessary. This principle of evidence-based treatment has not been fully adhered to in primary health care and hospitals as shown by findings of the irrational use of medicine, and these findings have become a chronic problem that is difficult to control. Irrational medicine use will give burden to society both from clinical and economic aspects, and therefore, government policy to protect people from such burden is indeed necessary. Commitment and collaboration from stakeholders are necessary to improve medicine use toward RUM in accordance with the principles of evidence-based treatment.

A survey conducted in 2001 by the WHO [1] showed that globally unnecessary use of antibiotics reached 50\%. Eighty countries reported chloroquine resistance for malaria treatment due to its excessive use, and in the United States, medicine adverse events were one of the six major causes of death. A study by Narayan and Mangesh [2] in India found that $79 \%$ of pediatric inpatients in tertiary care hospital received antibiotics. Experience this study that the number of drug per prescription remained about three, similar with other studies conducted by Narayan and Mangesh [2] in India and Karimi et al. [3] in Iran. Other problems that commonly found were too many medicines per prescription (polypharmacy) or medicines which were not used according to their indications. Other forms of irrational use of medicines included expensive treatment that could actually be less expensive if conducted appropriately and irrational self-medication, especially the use of inappropriate antibiotics and medicines that were not used according to the recommended dose or duration as mentioned by the WHO [4], Utarini [5], and Suryawati [6]. Studies conducted by Arura et al. in India revealed the rapid development of resistant Pseudomonas aeruginosa to antibiotics [7] and resistant Salmonella typhi to ciprofloxacin [8] due to inappropriate and inadequate use of antibiotics in hospitals.

Various interventions in RUM long been conducted, including in Indonesia, but these efforts could usually only result in short-term impacts. Failure of a RUM intervention may be due to an inappropriate selection of methods, i.e., intervention methods which are unsuitable with local organizational behavior, high resistance from the organization, inadequate attention to internal staff, and strong influence from outside the organization. Despite those difficulties in implementing 
RUM, Gunungkidul and Sleman Districts have successfully maintained RUM interventions over a long period of time as reported by Noor [9], Purwaningsih [10], and Yudatiningsih [11]. This success has become a very interesting case to investigate what factors enabling both districts to maintain the RUM intervention over the long term.

This study aimed to reveal the success factors for sustainable RUM interventions. Identification of success factors will be of beneficial to other districts to improve the RUM. The general objective of this study is to evaluate the capacity for sustainability after 20 years of implementation of RUM program in Gunungkidul and Sleman Districts. The specific objective of this study was to explore the management process in terms of how the District Health Offices adopted a research method into policy and at the end became part of the work culture in the PHCs.

\section{METHODS}

This is a single case study with non-experimental exploratory design. Quantitative and qualitative data collection was conducted in an integrated way (mixed-method research). Quantitative data sources included archives, notes/records, and documentation of monitoring and evaluation from district health offices and PHC related to the process and implementation of RUM. Qualitative data were collected using Focus Group Discussion (FGD) and in-depth interview methods.

Study sites were Gunungkidul and Sleman Districts. Separate FGDs were conducted among doctors, nurses, and midwives who were selected using simple random sampling method from 12 PHCs in each district. The criteria of FGD participants were senior staff who had at least 5 years working experience in PHC. In-depth interviews were conducted to explore the commitment of policymakers in the District Health Offices. The participants of in-depth interviews were the health policymakers at district level, who have first-hand knowledge on the implementation process of RUM program, i.e., heads of the two district health offices and pharmacy managers who were in position between the year of 1994 and 2014.

The quantitative data included polypharmacy, percentage of patients receiving antibiotics, and percentage of patients receiving injections. These data were collected from self-monitoring (SM) documentation of respective districts, and therefore, no mean \pm standard deviation could be calculated. Qualitative data were analyzed descriptively and were arranged chronologically in each district in cross-occurrence and time. The final results of the analysis are presented in the form of descriptive writing and pictures.

\section{RESULTS}

\section{RUM implementation process in Gunungkidul District}

The implementation of the RUM program in Gunungkidul District was conducted through several stages. The first stage was initially a research activity in collaboration with academics. It was started with the formation of RUM district team consisting of high officials of the District Health Office, officers in charge of district pharmacy, and senior PHC doctors. The task of the District RUM team was to identify priority issues in medicine use using selected indicators, i.e., polypharmacy, percentage of injection use, and percentage of antibiotics use.

Initial interventions were conducted using the Interactional Group Discussion (IGD) led by a team of researchers from the International Network for Rational Use on Drug-Indonesia and Gadjah Mada University. Activities were conducted by Hadiyono in 12 randomly selected PHCs and aimed to change the behavior of PHC prescribers for not using excessive injections. PHC doctors, nurses, midwives, and patients participated in the IGDs [12].

The second stage was a continuation of the first stage, using SM method as an effort to maintain RUM implementation independently as reported by Sunartono and Darminto [13]. The development of SM initiated with the training of doctors, nurses, and midwives from four selected PHCs based on the enthusiasm and progress achieved during the first stage. The PHC teams consisted of doctors, nurses, and midwives. They were trained to independently monitor the use of medicines in their respective PHC and sub-PHCs. The teams of the four PHCs collected 30 randomly sampled prescriptions with single diagnosis from PHC patients monthly. The three RUM indicators were then calculated and recorded in an SM format and reported to the District Health Office every 3 months. Assessment of SM results was done by comparing the results of the current month to the previous month. Therefore, the progress would be immediately seen. The final evaluation of the second phase was carried out together with all PHCs involved covering the processes, outcomes, and instruments of SM, and the evaluation result was used for taking corrective action.

The third stage was the implementation of SM in all PHCs in the district. It was obligatory to report the result of SM to the District Health Office routinely, and RUM evaluation was conducted every 3 months at the District Health Office. When a PHC was late to report or during the 3-month, its RUM profile did not show improvement or even tended to decline, then the district RUM team would supervise and help the PHC to solve the problem.

The implementation of SM instruments applied three strategies, i.e., educational, managerial, and regulatory strategies in a complementary way. Educational strategy involved serial workshops on RUM to develop commitment and training on RUM techniques. Managerial strategies included the establishment of PHC-level RUM teams, active participation of PHCs in medicine planning, routine reports, evaluation and feedback, and routine 3-monthly meetings at the District Health Office to create peer group pressure for PHC prescribers. Regulatory strategies included limiting medicine items to essential only in the planning, promotion of generics use of treatment guidelines, and improvement of procurement and distribution of medicines. Altogether, RUM intervention and implementation in Gunungkidul district were conducted using integrated quantitative and quantitative approach, as described in Fig. 1.

\section{RUM implementation process in Sleman District}

Similar with the Gunungkidul District, RUM activities in Sleman District began with research activity. Sleman District was one of the pilot test sites of RUM intervention conducted by Gadjah Mada University in collaboration with the WHO, in the treatment of acute diarrhea in children under 5 years old. The intervention used small group discussion (SGD) method compared with seminar method that was conducted by Santoso et al. [14]. In 1998, Sleman District Health Office performed SM replication with three indicators, i.e., polypharmacy, percentage of injection use, and percentage of antibiotics use. Evaluation and feedback were carried out at regular meetings at the District Health Office every 3 months. In the same year, Sleman District Health Office simultaneously implemented the policy which requires good understanding in RUM material for all new PHC doctors.

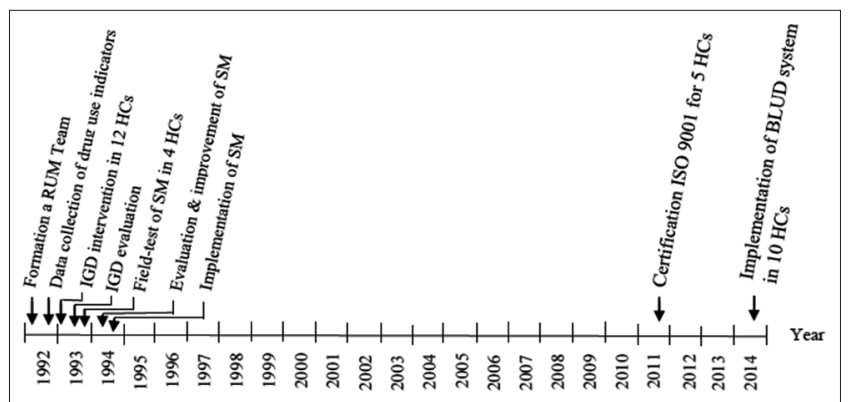

Fig. 1: Timeline of rational use of medicines implementation process in Gunungkidul District 
In the implementation of RUM, Sleman District Health Office also applied three strategies covering education, managerial, and regulation. First, educational strategy in various forms, including initial workshop, training on data collection, seminars on the results of data collection, discussion, and adoption of the SM instruments. Second, managerial strategies were the establishment of RUM Team in District Health Office, PHC involvement in medicine planning, regular meeting for evaluation and feedback, and supervision to PHC. Third, regulatory strategies in the form of implementation of RUM guidelines, use of generics and essential medicines, restrictions on medicine planning in PHC level, procurement, and storage of medicine were carried out by the District Health Office.

In 2000, interventions were conducted using monitoring-trainingplanning (MTP) method followed by feedback to reduce unnecessary antibiotics use in children with non-specific acute respiratory infections [10]. Follow-up monitoring and evaluation were conducted routinely by the District Health Office every 3 months. All activities in the implementation process of RUM in Sleman District are shown in Fig. 2.

\section{Monitoring of RUM indicators}

Documentation of RUM indicators in Gunungkidul and Sleman District Health Offices is still well preserved although there have been changes of staff due to the transfer of positions, promotions, or retirement. Polypharmacy in Gunungkidul District at the beginning of the RUM program was 4.2 , and it went down to 3 , then no data obtained until 2011. Polypharmacy monitoring results of the past 3 years were 2.41 in 2011, 3.04 in 2013, and 2.89 in 2014. On the other hand, in Sleman District, polypharmacy data remained at around 3 over a period of time from 1998 to 2014. Long-term data on polypharmacy in Gunungkidul and Sleman Districts are presented in Table 1.

Initially, the use of injection in Gunungkidul District was as high as 68.05\% of all patients in 1992, then it went down to $20.62 \%$ after IGD intervention in 1993, and after SM intervention, the percentage of patients receiving injection continued to fall to $9.23 \%$ in 2001 . Then, in 2011, just like indicators of polypharmacy, indicators in the use of injection were not obtained in the period of 2001-2011, while data on use of injection from the past 3 years were $2.2 \%$ of patients in 2012, 3.6\% of patients in 2013, and $0 \%$ in 2014. On the contrary, in Sleman District, the use of injections was already quite low since the beginning of the program, i.e., $4.97 \%$ of patients in 1998, and it fell to $0.18 \%$ of patients in 2014 .

The use of antibiotics in Gunungkidul District at the beginning of the program in 1992 reached $62.1 \%$, then dropped to $52.1 \%$ after IGD intervention. After SM intervention, it decreased to 33.64\% in 2001 . As in the case of polypharmacy and the use of injections, no data on antibiotics use were documented between 2001 and 2011, while antibiotics use in the past 3 years were 15.1\% in 2012, 21.8\% in 2013, and $24.1 \%$ in 2014. In Sleman District, data can be presented over a period of time between 1998 and 2014. Antibiotics use in 1998 reached $44.31 \%$ and it dropped to $20 \%$ in 2003 , then it stayed in that range to 2014. The dynamics on the percentage of injections and antibiotics use

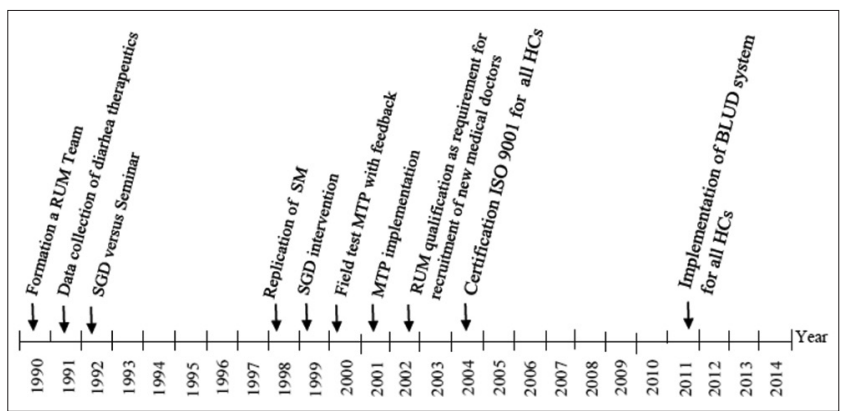

Fig. 2: Timeline of rational use of medicines implementation process in Sleman District in Gunungkidul and Sleman District during the observation period are presented in Table 2 .

\section{DISCUSSION}

Culturization of rational prescribing among health providers is the key for sustainable program

The irrational use of medicine in $\mathrm{PHC}$ is the result oflong-term interaction between prescribers, patients, environment, and organizational policy that becomes a habit, and furthermore, it eventually becomes an organization culture. However, the use of medicines in PHC is more determined by prescribers regarding medicine selection, dosage, duration of time, and medication, as prescribers are more well informed about diseases and which medicines are best suited for certain patients. In accordance with the theory, every individual will learn to imitate various repeated actions, which means that there will be a process of inheritance of tradition. By repeatedly imitating others, individual actions will slowly become a steady pattern and norm that will govern the individual's action, or in other words, there is a process of integration of action to culture as mentioned by Juanda [15] and Budiyanto [16].

Therefore, changes cannot be made only through conducting tests for the intervention instrument, but changes should be able to penetrate into the local management system, so that it can be regularly monitored and evaluated. This is in line with MDS-3 [17] which states that regular teaching and monitoring by medical officer with attention to the medical workers' prescribing habits are essential to maintain the positive alteration. An analysis by Laing et al. [18] revealed that simple approaches such as dissemination of prescribing information and treatment manuals have been proven ineffective in improving medicine use. The long-term uninterrupted RUM implementation resulted in positive change of medical treatment culture in PHC. This change was achieved through a long process involving various programs over two decades. This long process goes in accordance to Javanese phrase of wisdom which states that the success of a change required four consecutive stages i.e., dipeksa (being forced), kepeksa (forced), biasa (become habit), and budaya (culture) [19]. This four-stage process is what the

Table 1: Polypharmacy in Gunungkidul and Sleman Districts during 1992-2014

\begin{tabular}{lll}
\hline \multirow{2}{*}{ Year } & \multicolumn{2}{l}{ Number of items prescription* } \\
\cline { 2 - 3 } & Gunungkidul District & Sleman District \\
\hline 1992 & 4.2 & + \\
1993 & 4.1 & + \\
1994 & 3.13 & + \\
1995 & 3.11 & + \\
1996 & 3.07 & + \\
1997 & 3.12 & + \\
1998 & 3.09 & 3 \\
1999 & 3.13 & 2.95 \\
2000 & 3.26 & 2.75 \\
2001 & 3.02 & 2.99 \\
2002 & - & 2.84 \\
2003 & - & 3.40 \\
2004 & - & 3.28 \\
2005 & - & 3.16 \\
2006 & - & 3.24 \\
2007 & - & 3.23 \\
2008 & - & 3.21 \\
2009 & - & 3.17 \\
2010 & - & 3.34 \\
2011 & - & 2.61 \\
2012 & 2.41 & 2.64 \\
2013 & 3.04 & 2.72 \\
2014 & 2.89 & 3.10 \\
\hline & &
\end{tabular}

*Secondary data. SD values are not available. -: Data not recorded. +: RUM program just started ill 1998. SD: Standard deviation, RUM: Rational use of medicines 
Table 2: Percentage of patients receding injections and antibiotics in Gunungkidul and Sleman 11 Districts during 1992-2014

\begin{tabular}{|c|c|c|c|c|}
\hline \multirow[t]{2}{*}{ Year } & \multicolumn{2}{|c|}{ Gunungkidul District } & \multicolumn{2}{|l|}{ Sleman District } \\
\hline & Injection* (\%) & Antibiotic* (\%) & Injection* (\%) & Antibiotic* (\%*) \\
\hline 1992 & 76 & 63 & + & + \\
\hline 1994 & 20.62 & 33.17 & + & + \\
\hline 1995 & 12.84 & 28.09 & + & + \\
\hline 1996 & 12.4 & 26.09 & + & + \\
\hline 1997 & 14.64 & 27.44 & + & + \\
\hline 1998 & 11.64 & 28.09 & 4.97 & 44.31 \\
\hline 1999 & 12.94 & 30.98 & 2.63 & 49.5 \\
\hline 2000 & 12.15 & 11.34 & 18 & 35.64 \\
\hline 2001 & 9.23 & 33.64 & 1.51 & 29.77 \\
\hline 2002 & - & - & 0.6 & 31.I8 \\
\hline 2003 & - & - & 0.8 & 20.43 \\
\hline 2004 & - & - & 0.44 & 21.75 \\
\hline 2005 & - & - & 0.38 & 26.9 \\
\hline 2006 & - & - & 0.25 & 21.53 \\
\hline 2008 & - & - & 0.26 & 12.64 \\
\hline 2009 & - & - & 0.25 & 18.21 \\
\hline 2010 & - & - & 0.08 & 19.41 \\
\hline 2011 & - & - & 0.16 & 19.25 \\
\hline 2012 & 2.2 & 15.1 & 0.15 & 19.08 \\
\hline 2013 & 3.6 & 21.8 & 0.17 & 17.01 \\
\hline 2014 & 0 & 24.09 & 0.18 & 19.3 \\
\hline
\end{tabular}

*Secondary data. SD values are not available. -: Data not recorded. +: RUM program just started in 1998. SD: Standard deviation, RUM: Rational use of medicines

authors meant by culturization. Therefore, it is necessary to create a condition of PHC prescribers to carry out the RUM even if initially it was carried out merely as a forced necessity. In this case, the policymakers in district health office have been equipped with such authority and power. It is necessary, therefore, to get commitment from the policymakers in district health office. Commitment of the policymakers in District Health Office has the power to make changes in rational treatment and RUM, and it will certainly be followed by the prescribers in PHC. The strength of the policymakers in district health office is due to their position as top managers. As stated by Bacharah and Lawler [20], Robbins and Judge [21], and Omisore and Nweke [22], sources of a leader's power may come from legitimacy, expertise, reward, and coercion.

The commitment from health policymakers is very effective because it is manifested in concrete actions, such as the implementation of rules, budget support, guidance, monitoring, and evaluation on a regular basis so that the RUM program runs optimally. This result demonstrates how the support of the district health policymakers will facilitate the transfer of research activities into routine programs in the district health office. This is in line with the theory by Allur et al. [23] and Fakoya [24] which states that the role of leaders is needed in the internalization of policies that have been established to be implemented and become routine activities and programs.

\section{The important role of district policymakers}

Every effort to improve the quality of medication in health service means an action to change organizational culture. Successful culturization of RUM program is not solely determined by the method used, but it is more influenced by the approach used by policymakers in the District Health Office. The application of various methods simultaneously, as presented in Figs. 1 and 2, is consistent with MDS-3 [17] which states that combination of different intervention types is likely to be synergistically increased the impact and Sudjito's statement [25] that there is no single and universal method. Every method can be selected and become the correct method, when they are correlated with the logical level of thinking, and rational understanding, and are appealing for the targeted community.

There are many options for effective RUM intervention methods, for example, IGD [12], MTP [11], and also SGD and seminar methods [14].
Other studied by Kristin et al. [26], using evidence-based hospital medicine formularies, had significantly reduced antibiotics use $(12.5 \%$ vs. $6.9 \%$; $<<0.05$ ) in private hospitals in Tanjung Enim.

This study revealed that whatever method is used, as long as it is encorporated into the local system, will lead to the success of the program. A starting point in selecting intervention method is to clearly define the problem that needs to be solved. Suryawati [6] stated that, to improve the irrational use of medicine, local wisdom is needed to explore the causes of problems and which methods would be suitable for local settings. In other words, cultivating RUM culture would only be effective if it corresponds to the social structure of the setting.

According to Buse et al. [27] to implement policy changes, three approaches that can be chosen are: Top down, bottom up, and delegation to third parties or agents. All three approaches can be used, but delegation to third parties poses a risk of dependence and conflicts of interest from the third parties. Omisore and Nweke state that appropriate use of power leads to the achievement of desired goals and objectives [22]. In RUM intervention, the selected approach should be able to provide education and to encourage active participation of the PHC prescribers to ensure the success and sustainability of the RUM program. The top-down approach was very effective at the beginning of the RUM intervention, applying both educational and managerial strategies.

The implementation of the RUM program is considered successful if there is a change of behavior from the PHC prescribers. This process of behavior change can be achieved through continuous education as reported by Juanda [14], Costa and de Matos [28], and Sunardi and Maryadi [29]. Cumming et al. [30] stated that in the organization change process can be done through communication, involvement in decisionmaking, involvement in problem-solving, and strong leadership. Regular monitoring and evaluation of RUM programs by the District Health Office showed a continuous coordination and communication as well as involvement of policymakers. As it is commonly known, one of the leaders' functions is to find solution for organizational problems (problem solvers) and as policymakers (decision makers) as mentioned by Albrecht [31] and Mukhlas [32]. Therefore, district health policymakers need accurate information about the problem of medicine 
use in PHC, and it can only be obtained through good communication with staff and other stakeholders. This is in accordance with the theory explained by Mukhlas [32] which states that a leader must be able to ensure good communication for making coordination work.

The bottom-up approach is essential to encourage active participation of the PHC prescribers because PHC prescribers have major role in medicine use. Active participation of PHC prescribers is very useful to maintain the result of intervention so that sustainability of program can be achieved. The success of this change in the organization does require the involvement of all members of the organization from planning, implementation, and routine evaluation as mentioned by Albrecht [31] and Cotache et al. [33].

This capacity for sustainability of the RUM program is seen in how it is accepted as a culture in the treatment process in PHC. Therefore, the RUM implementation will continue and is not affected by the change in personnels' position in the organization. This result is in line with Nuryanti's theory which states that the implementation of technology from outside the organization will persist for a long time if it can be accepted and it has become rooted as a social value in the organizational system [34].

\section{Strengthening district health offices through the development of} RUM program

Irrational use of medicine is a long-persistent global problem that can be found in both developed and developing countries even today [4-6,35]. However, implementation of RUM program is essential, and thus, it needs the policy from government to overcome this problem as mentioned by Laing et al. [18]. Political commitment from all stakeholders is therefore very important. Excellent policy without culturization is nothing, and thus, the role of district health policymakers is very important in decentralization era.

As widely known, the negative impacts of the irrational use of medicines can be very broad, including economic losses, the occurrence of medicine side effects, increased medicine resistance, prolonged illness, or even death $[1,4,17,36]$. Many efforts to improve irrational use of medicine in the region often face some constraints, such as lack of human resources, lack of commitment from policymakers, or weak organizational structure and information system. However, these constraints are not excuses for centralization, instead, they are challenges for the government to strengthen districts through the RUM program considering the negative impacts of irrational medicine use.

Centralization of the burden and responsibility of the RUM program in the national level will require a long time and high cost, and therefore, it is necessary to immediately empower district health offices with intensive control from the national government. One of the reasons for the strengthening of the district health offices in the RUM program is to accelerate the expansion of the program coverage to prevent larger losses due to the many negative impacts of irrational medicine use.

Culturization the RUM program in health facilities requires a regular monitoring and evaluation by the policymakers. Therefore, it will be more appropriate and will need less time if they were conducted by the District Health Offices as compared to if they were conducted nationally by the central government. This recommendation is in line with the states that intervention activities should be followed by regular monitoring and evaluation to ensure the continuous process of change $[17,20]$.

The central government needs to facilitate the District Health Office to increase their capacity such as training of trainer, creating peer group at province and national level, building effective management information system, and providing incentive or disincentive, and whenever appropriate prescribing restriction. Thus, it is important to build a commitment from the district health policymakers.

\section{CONCLUSIONS}

Based on the results of this study, it can be concluded that the concept of RUM with the principle of evidence-based medical treatment can be implemented in the PHC. To ensure the sustainability of RUM implementation, it is necessary to integrate the RUM concepts in the organization culture, to be absorbed by PHC staff to ensure the sustainability of RUM program and to synchronize it with other programs. Furthermore, it is suggested that all district health offices cultivate the concepts of rational treatment using evidence-based methods in all healthcare units in their working areas through the District Health Office routine activities.

\section{ACKNOWLEDGMENT}

The completion of the study would not have been possible without the support and invaluable contribution made by Chief Pharmacist and staff of District Pharmacy Section and all PHC's staff of Gunungkidul and Sleman Districts Health Office. The authors would like to thank Dra. Winarni M.Kes, Dra. Purwaningsih M.Kes, Dra. Prima Walani, Dra. Trisniyati, Dra. Titik, and Dra. Herlin for data collection and technical assistance.

\section{AUTHORS CONTRIBUTION}

Study proposal was prepared by H. Sunartono and S. Suryawati. YS Prabandari contributed on qualitative method and $\mathrm{H}$ Kusnanto on policy analysis. Data collection and primary analysis was conducted by $\mathrm{H}$. Sunartono. All authors participated in further analysis and data presentation in various degrees. Manuscript was prepared by $\mathrm{H}$. Sunartono and S. Suryawati, all authors reviewed and agreed on the final manuscript.

\section{CONFLICT OF INTEREST}

All authors declared no conflict of interest regarding the study and the publication of this paper. No external funding was received to support the study.

\section{REFERENCES}

1. World Health Organization. Promoting Rational use of Medicines Saves Lives and Money. Geneva: Mediocentre; 2004. Available from: http://www.who.int/mediacentre/news/notes/2004/np9/en/index.html. [Last accessed on 2016 Dec 02].

2. Narayan DS, Mangesh MM. A study of prescription pattern of antibiotics in pediatric in patients at a tertiary care hospital in central India. Int J Pharmacol Res 2016;6:286-90.

3. Karimi A, Haerizadeh M, Solemani F, Haerizadeh M, Taheri F. Evaluation of medicine prescription pattern using World Health Organization indicators in Iran: A cross-sectional study. J Res Pharm Pract 2014;3:39-45.

4. World Health Organization. Country Pharmaceutical Situations; Report Fact Book on WHO Level 1 Indicators, WHO/EMP/MPC/2010.1. Geneva: WHO; 2007. Available from: http://www.apps.who.int/ medicinedocs/documents/s16874e/s16874e.pdf. [Last accessed on 2016 Dec 02].

5. Utarini A. Mutu Pelayanan Kesehatan di Indonesia: Sistem Regulasi Yang Responsif, Professorship Inauguration Speech at Faculty of Medicine. Yogyakarta: Universitas Gadjah Mada; 2011

6. Suryawati S. Kearifan Budaya Lokal Untuk Solusi Masalah Global Penggunaan Obat, Professorship Inauguration Speech at Faculty of Medicine. Yogyakarta: Universitas Gadjah Mada; 2012.

7. Arora D, Jindal N, Kumar R, Romit M. Emerging antibiotic resistance in pseudomonas-achallenge. Int J Pharm Pharm Sci 2011;3:82-4.

8. Arora D, Gupta P, Gill G, Chawla R, Singla R. Changing trends in the antibiograms of Salmonella isolates in Northern Area of Punjab. Int J Pharm Pharm Sci 2010;2:135-7.

9. Noor R. Pengaruh Peraturan Daerah Kabupaten Gunungkidul Nomor 14 Tahun 2000 Tentang Retribusi Pelayanan Kesehatan Terhadap Pola Peresepan Rawat Jalan Di Puskesmas (Theses), Post-Graduate Program of Public Health. Yogyakarta: Universitas Gadjah Mada; 2003.

10. Purwaningsih S. Evaluasi Penerapan Peraturan Daerah Kabupaten 
Gunungkidul Nomor 14 Tahun 2000 Tentang Retribusi Pelayanan Kesehatan Terhadap Ketersediaan Obat Di Puskesmas (Theses), Postgraduate Program of Public Health. Yogyakarta: Universitas Gadjah Mada; 2002.

11. Yudatiningsih I, Suryawati S. The impact of feedback on monitoringtraining-planning (MTP) results in acute respiratory tract infection therapy in health centers at Sleman district. J Manajemen Pelayanan Kesehatan 2004;7:41-9.

12. Hadiyono JE, Suryawati S, Danu SS, Sunartono, Santoso B. Interactional group dicussion; result of a controlled trial using a behavioral intervention to reduce the use of injections in public health facilities. Soc Sci Med 1996;42:1177-83.

13. Sunartono D, Darminto B. From research to action: The Gunungkidul experience. Essent Drugs Monit 1995;20:21-2.

14. Santoso B, Suryawati S, Prawaitasari JE. Small group intervention vs formal seminar for improving appropriate drug use. Soc Sci Med 1996;42:1163-8

15. Juanda N. The role of formal education in culturalization process. Lentera Pendidikan 2010;13:1-15.

16. Budiyanto. Proses Pembudayaan Melalui Internalisasi, Sosialisasi, Enkulturasi, Difusi, Akulturasi, dan Asimilasi. Budiyanta's Blog; 2010. Available from: https://www.budiyanta.wordpress.com/2011/06/18. [Last accessed on 2014 Jan 22].

17. Managing Drug Supply (MDS). Managing Access to Medicines and Health Technologies. $3^{\text {rd }}$ ed. Arlington, VA: Management Sciences for Health; 2012. Available from: http://www.msh.org/news-events/pressroom/managing-drug-supply-third-edition--now-available-online. [Last accessed on 2013 Dec 21].

18. Laing RO, Hogerzeil HV, Ross-Degnan D. Ten recommendation to improve use of medicine in developing countries. Health Policy Plann 2001;16:13-20.

19. Anonymous. Golden Words that have been Transferred over Generations among Javanese. Personal Communication.

20. Bacharah SB, Lawler EJ. Power and Politics in Organizations. San Fransisco: Jossey-Bass; 1980.

21. Robbins SP, Judge TA. Organizational Behavior. $15^{\text {th }}$ ed. New Jersey: Pearson Education, Inc., Publishing as Prentice Hall; 2013. Available from: http://www.bba12.weebly.com/uploads/9/4/2/8/9428277/ organizational behavior $15 \mathrm{e}$ - stephen $\mathrm{p}$ robbins timothy a judge_pdf_qwerty.pdf. [Last accessed on 2017 Mar 07].

22. Omisore $\mathrm{BO}$, Nweke AN. The influence of power and politics in organization. Int J Acad Res Bus Soc Sci 2014;4:164-83.

23. Allur E, Heras-Saizarbitoria I, Casadesus M. Internalization of a Longitudinal Survey-ProQuest. Vol. 114. Spain: Indutrial \& Data Systems; 2014. p. 872-85.

24. Fakoya MB. Forced internalization of external environmental cost experience of a South African company-ProQuest, Limpopo, South Africa. Environ Dev Sustain 2014;16:797-807.

25. Sudjito SH. Pembudayaan Pancasila. Jakarta: Badan Intelijen Negara Republik Indonesia; 2014. Available from: http://www.bin.go.id/ wawasan/detil/190/3/07/02/2013/pembudayaan-pancasila. [Last accessed on 2014 Jan 22].

26. Kristin E, Anggraini DI, Thobari JA, Yasmina A. The effect of the implementation of evidence-based drug formulary on antibacterial use in a private hospital at Tanjung Enim, Sumatera Selatan, Indonesia. J Med Sci 2017;49:16-22.

27. Buse K, Mays N, Wait G. Making Health Policy; Understanding Public Health. England: Open University Press; 2005.

28. Costa LA, de Matos JA. Attitude change in arbitrarily large organizations. Comput Math Organ Theory 2014;20:219. Available from: https://www. doi.org/10.1007/s10588-013-9160-3. [Last accessed on 2017 Jul 19]

29. Sunardi, Maryadi S. The effectiveness of a two-day inclusion workshop on teachers; attitudes, understanding, and competence in inclusive education-ProQuest. World J Educ 2014;4:77-85.

30. Cummings TG, Worley CG, Calhoun JW. Organization Development and Change. $9^{\text {th }}$ ed. USA: South Western Cengage Learning; 2009.

31. Albrecht K. Organization Development. New Jersey: Prentice Hall, Inc., Englewood Cliffs; 1983

32. Mukhlas M. Perilaku Organisasi 1. Yogyakarta: Magister Manajemen Rumahsakit Universitas Gadjah Mada; 1994

33. Cotache BM, Funar SP, Adamescu D. Organization culture in implementing quality management system. In: Annals of DAAAM for 2009 and Proceeding of the $20^{\text {th }}$ International DAAAM Symposium; 2009. p. 1463-5.

34. Nuryanti W. Pembangunan Teknologi Berbasis Budaya, Plenary Lecture at $66^{\text {th }}$ Dies Natalis of Engineering Higher Education. Yogyakarta: Faculty of Engineering Universitas Gadjah Mada; 2012.

35. Hogerzeil HV. Promoting rational prescribing: An international perspective. Br J Clin Pharmacol 1995;39:1-6.

36. Bisht R, Katiyar A, Singh R, Mittal P. Antibiotic resistance-a global issue of concern. Asian J Pharm Clin Res 2009;2:34-9. 